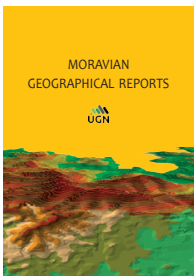

MORAVIAN GEOGRAPHICAL REPORTS

The Czech Academy of Sciences, Institute of Geonics

journal homepage: http:/www.geonika.cz/mgr.html

doi: https://doi.org/10.2478/mgr-2020-0022

\title{
Meaningful everyday life projects and activities in breast cancer survivors
}

\author{
Eva MAGNUS ${ }^{\text {a }}$, Klara JAKOBSEN ${ }^{\text {a }}$, Randi Johansen REIDUNSDATTER ${ }^{\mathrm{b}}$
}

\begin{abstract}
The time-geographic diary, supplemented by interviews, is presented in this study as a useful method to demonstrate that desirable everyday life projects, with associated activities, may positively influence an individual's quality of life. Breast cancer survivors can experience challenging everyday life activities due to late effects of treatment. Despite improvements in survivorship follow-up programs, we still lack knowledge about how the women themselves prioritise activities that are positive in everyday life. The aim of the present study was to identify everyday life projects that improve the quality of life in breast cancer survivors. The multi-method design included the time-geographic diary method and in-depth semi-structured interviews, carried out with a sample of fifteen breast cancer survivors. The interviews were performed with stimulus from the diary notes and consecutively analysed by directed content analysis. Meaningful everyday life activities were emphasised, and four projects were generated: 1) To do what is good for my body and soul; 2) To create something that is nice and for joy; 3) To keep my family and social network together; and 4) To keep my mind active. These findings can be directed to the development of more individual and peer-driven health care services.
\end{abstract}

Keywords: Breast cancer survivors, time-geographic diary method, in-depth semi-structured interviews, everyday life, activity, project

Article history: Received 10 March 2020, Accepted 2 September 2020, Published 31 December 2020

\section{Introduction}

Everyday life is shaped by what the individual gives preference to and decides to do, in between the struggle to reach desirable goals and handle restrictions (Ellegård and Wihlborg, 2001). In this way, everyday life is individual and personal, and at the same time, it is influenced by other people and by societal structures. Everyday life consists of many activities that can be seen as parts of different projects. In time geography, projects consist of all activities an individual does to reach a goal (Ellegård, 1999). Knowledge about the complexity of human activities can be found, inter alia, in occupational science (Cristiansen and Townsend, 2014; Hasselkus, 2006). When performing activities, the individual occupies a 'place in time in a rich tapestry of experience, purpose and meaning' (Christiansen and Townsend, 2014, p. 2). What people do, like making a meal or walking the dog, is often presented as ordinary, normal, or basic and seen to be of little importance (Hasselkus, 2006). Knowledge of what people do can be made more explicit, however, as there is a need to deepen our understanding of how people occupy themselves on an everyday basis (Christiansen and Townsend, 2014). The daily creation of everyday life is a challenge for most people, and for people living with illness or lasting effects from earlier illness, the challenge is even harder. This study deals with how breast cancer survivors experience activities in creating their everyday life.

\section{Previous research}

In cancer survivorship there is increasing knowledge about everyday life challenges caused by the disease and late effects of treatment, such as pain, night sweats, disrupted sleep, weight gain, and lymphedema (Jakobsen et al., 2017; Lindberg et al., 2015; McDougall et al., 2014; Ridner et al., 2012; Salander et al., 2011).

Although dealing with late effects is reported to be challenging, changes in life priorities and social support are positive aspects and ways of coping with the illness (Lindberg et al., 2015). Other ways of support in coping are time-relevant information and guidance (Jakobsen et al., 2017), stimulating environments and emotional

\footnotetext{
${ }^{a}$ Department of Neuromedicine and Movement Science, Norwegian University of Science and Technology, Trondheim, Norway (*corresponding author: E. Magnus, e-mail: eva.magnus@ntnu.no)

${ }^{\mathrm{b}}$ Department of Circulation and Medical Imaging, Norwegian University of Science and Technology, Trondheim, Norway
} 
support (Palmadottir, 2010), participating in social activities, regular physical activity, and community-based activities that one finds enjoyable (English et al., 2008). When living with distressing losses after cancer treatment, working toward normalcy may constitute the core process of recovery. The participants in a study by Walker et al. (2015) used different strategies such as taking control of the body and everyday routines, interpreting symptoms as what is to be expected with normal ageing, focusing on the needs of others, expanding their life space, and making plans for the future. A greater sense of normality was associated with higher engagement in valued activities and increased physical and psychological well-being (Walker et al., 2015).

Breast cancer and its treatment may impact women's everyday lives in various ways. In thematic interviews of 39 breast cancer survivors, some women experienced a positive cancer-initiated transformation in their lives, as the disease implied a break from a stressful working life. The experience of being cared for and being acknowledged in a new and positive way helped them to live better lives than before. Others said that the cancer passed without marked traces, and others reported that the cancer made both positive and negative changes in their lives. The positive experiences were improved relationships, a different life perspective, and more meaningful leisure time, while the negative was associated with health problems that restricted everyday life (Salander et al., 2011).

Many lifestyle interventions, often led by health professionals aiming to promote behavioural changes and psychosocial benefits in cancer survivors, have been successful. After a one-and-a-half-day educational program consisting of fitness, nutrition, and exercise related to health, more than $80 \%$ of the participants reported increased knowledge of the topic (Stoutenberg et al., 2011). There are several ways to increase exercise frequency in breast cancer survivors, such as emphasising a supportive environment, providing for timely, accurate, and tailored information, as well as knowledgeable instructions (Lavallée et al., 2019). A five-week group session (6-8 persons) focusing on energy conservation strategies, was shown to be effective in decreasing cancer-related fatigue and promoting a healthy lifestyle (Sadeghi et al., 2016), while eight weeks of yoga intervention was found to promote mental, physical, and social health in breast cancer survivors (Puymbroeck et al., 2013). In rehabilitation programs, important factors to consider are physical activity, psychoeducation, peer-topeer support, and follow-up over time (Hauken et al., 2013). In addition, women's needs as occupational beings are important to emphasise (Palmadottir, 2010).

Not all intervention programs have been successful. A systematic review of 26 studies of home-based multidimensional survivorship programs for breast cancer survivors, revealed that the programs had short-term beneficial effects on quality of life and that group-based programs may be more effective than individual programs (Cheng et al., 2017). Although a systematic review revealed that exercise history is positively associated with exercise adherence, we need further evidence on how social and environmental, as well as demographic, psychological, and physical determinants, influence exercise adherence and maintenance. More research is still needed to determine the key components of interventions (Kampshoff et al., 2014).

Group interventions are feasible for many, but individuals have different experiences of coping and control and need to find a balance between different areas in life (Hauken et al., 2013). Hence, a 'one-size-fits-all' intervention will not cover their needs, and for some cancer survivors, group interventions are not even desirable (Johansen and Dalton, 2017). Evidence of more individual and "lowthreshold" approaches that could promote favourable healthbehavioural change and health-related benefits are required (Denmark-Wahnefried et al., 2006; Palmadottir, 2010; Johansen and Dalton, 2017). More knowledge about how breast cancer survivors themselves prioritise activities in their everyday lives could be essential for this purpose. Time-geography, in which activities and projects are central concepts, can be a suitable "tool" to gain a deeper understanding of the meaning and experiences of people's everyday lives (Ellegård, 2019).The primary aim of this study was therefore to identify important everyday life projects that improve the quality of life in breast cancer survivors.

\section{Theoretical background}

Since occupational science is an interdisciplinary research discipline, with a goal to explore and understand the nature, meaning, and sociocultural structures of occupation (Jarman, 2014), researchers from fields like anthropology, economics, geography, occupational therapy, political science, psychology and sociology are dealing with studies of everyday life. They all suggest, however, that occupations emerge from the routine and everyday aspects of humans daily living, and they all contain the same assumption, namely that everyday living is actually a very complex process (Jarman, 2014).

In situations where too many or too few daily activities lead to an imbalance, the result can easily create a stressful situation of dissatisfaction - and an activity balance may be needed. Håkansson et al. (2017) describe activity balance as a dynamic concept moving between more or less activities, where the individual influenced by surroundings self must decide the degree of balance. By defining activity balance, the individual's perception of having the right amount and variation of activities are central (Wagman et al., 2012). Backman (2014) emphasise the extent to which the individual is able to organise and participate in desirable activities in accordance with his or her aspirations and values. Moreover, what must be considered as valued activities can differ over the course of a lifetime and depends on cultural conditions. A literature review of occupational science describes how occupational balance depends on the individual's perception of the variation and the right amount of activities (Wagman et al., 2012). Time spend in activities will therefore be insufficient knowledge when studying activity balance, because we need to know the subjective individual meanings of the activities (Håkansson et al., 2017).

To understand and describe activity balance in the present study, knowledge from studies of Backman (2014) and Wagman et al. (2012) will be important in order to understand the individual's perception of an everyday life activity balance. These studies also clarify the importance of the individual's experience and their values of what activities are worth spending time on. The way of prioritising time is often connected to the individual's identity. In the present article, the concept of activity is used similarly to that of occupation, as in disciplines such as time geography.

In occupational science, identity is often connected to purposeful and meaningful activities (Jarman, 2014; Townsend, 1997). What people do in everyday life is understood to be linked to the development and expression of identity (Christiansen, 1999; Laliberté Rudman, 2002), 
which means that the individuals will express themselves and their identity in various activities, at work, in leisure time, and at home with family and friends. Challenges performing desirable activities, as after illness, may therefore imply difficulties in expressing identity, as before the disease.

\section{Design and methods}

The study adopted a multi-method design, including the time geographic diary method (Ellegírd and Nordell, 1997) and in-depth qualitative interviews (Gubrium and Holstein, 1997). As a first phase topics from the diary were used as a starting point and as stimulus material for the interviews. In the next phase interviews were conducted based on themes prepared in an interview guide (Anguera et al, 2019).

\subsection{Recruitment and participants}

'Everyday life in cancer survivors' is a qualitative subproject of a long-term (median 8 year) clinical follow-up study of breast cancer patients at Trondheim University Hospital. The patients were recruited from the Health Region Middle Norway, which represent one of four health regions in Norway (see Fig. 1). At the outpatient clinic, the consulting oncologist invited the patients consecutively to participate. Participation in the present sub-study involved writing diary for one week, including the weekend, and subsequently agreeing to participate in an individual interview. The data collection for this part took place in 2013.

After receiving the completed diaries, the researchers called participants and made appointments for the interviews. There was no selection of participants based on any specific characteristics. The interviews were consecutively

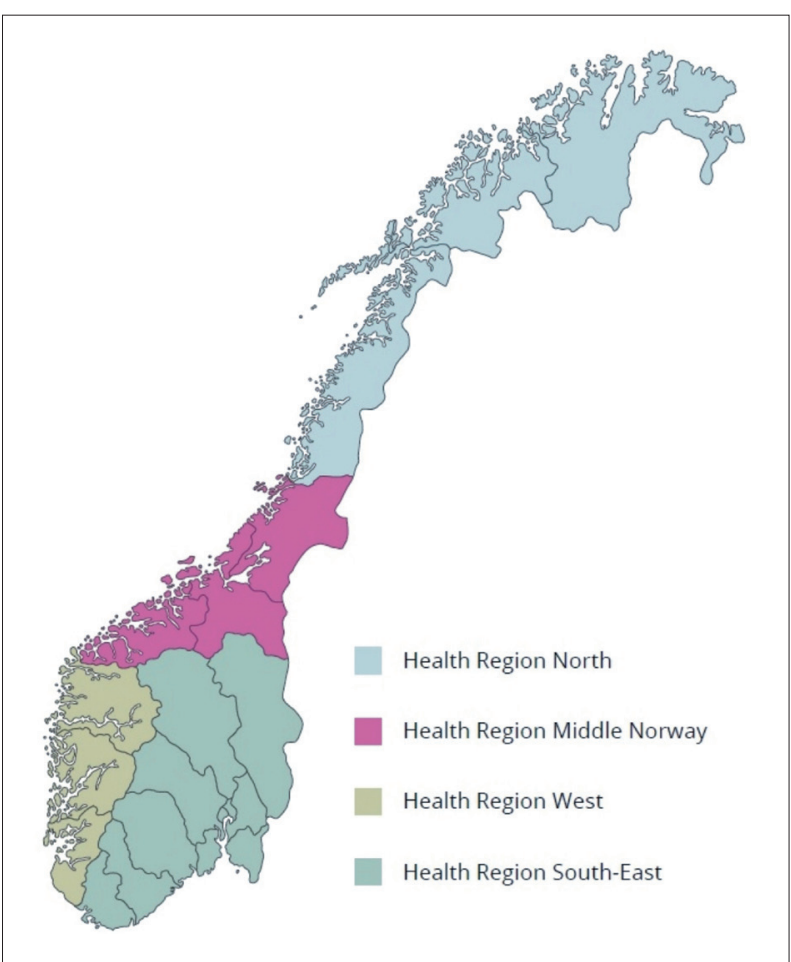

Fig. 1: The four health regions in Norway

Source: authors' elaboration analysed, and participants were included until saturation of information was reached (Malterud et al., 2015). Fifteen women participated ${ }^{1}$.

\subsection{Generation of data}

\subsubsection{The time geographic diary method and in-depth} interview

The time geographic diary method focuses on what people do and the connection between time, space, and activity, where the activity is the main focus (Ellegård and Nordell, 1997; Magnus, 2019). It illustrates routines as well as preferred and chosen activities in a social and geographical context. The method relies on a diary notebook that is filled out by participants, where all activities from one midnight to next midnight are reported. The diary illustrates a rhythm shaped by sleep and meals, and diaries from different individuals are, of course, not identical and cannot easily be compared. They do, however, give a picture of characteristics of the everyday life of the individuals, which is worthy for many purposes. The diary notebook has columns for time, what the diarist does (activities), where the diarist acts (places), and with whom (togetherness), and at last the diarist's own comments.

The participants were asked to list activities in such a diary notebook for seven consecutive days and to write down comments during the day, starting when getting up in the morning. Each diary was read thoroughly to obtain specific knowledge of each participant's everyday life activities in context. The intention was to discover what activities the individual found important in everyday life to be able to live a good life.

Based on knowledge from the diary week, a semistructured interview was conducted with each diarist, either at the participant's home or at an arranged meeting place. The interviews started with a recap of the information in the individual's diaries. The main question in the interview guide was: 'Tell me about your everyday life today', followed by the question, 'In what ways has breast cancer influenced your everyday life?'. These main questions were followed by questions about how the women chose to use their time, changes in daily activities, and the meaning of different elements in the environment. With the intention of capturing the individual's projects, diary notes on activities interpreted with a special meaning were given particular attention during the interview. The interviews were all conducted by the authors, electronically recorded, and literally transcribed.

\subsubsection{Analysis of the interviews}

The interviews were analysed by a directed content analysis (Hsieh and Shannon, 2005), which starts with existing research on the phenomenon under research or a theory as guidance for initial codes. The goal of a directed approach to content analysis is to validate or extend conceptually a theoretical framework or theory. Existing theory or research can help focus the research question. It can provide predictions about the variables of interest and about the relationships among variables, thus helping to determine the initial coding scheme or relationships between codes.

In the transcribed interviews, what was found to be central and desirable activities and restrictions (Ellegård, 2019) in everyday life, were manually highlighted and then gathered

\footnotetext{
${ }^{1}$ Ethics: The main study was approved by the Regional Committee for Medical and Research Ethics (REK midt id 13760). All participants gave their written informed consent after being provided oral and written information.
} 
into a short-synthesised text from each interview. Further analysis of each synthesised text identified desirable activities that were grouped and given names: 1) 'Physical activities'; 2)'Creative activities'; 3)'Activities for the brain'; 4) 'Activities in the home'; and 5) 'Activities together with others' (see Tab. 1). The presented activities were influenced by different kinds of challenges, and they held different meanings for each individual. Various combinations of desirable activities were performed by the individual women in order to achieve the goals for their projects.

The identification of projects was carried out by combining the activities from the diaries and interviews, with the meaning of these activities expressed in the interviews. For example, notes in the diary about walking the dog together with a friend were elaborated in the interview, talking about how this activity was performed, where and with whom, and the meaning of it. The meaning could be the importance of physical activity to gain more energy, to be together with a friend, or to just be with the dog.

In time geography, projects are associated with all the different activities an individual does to reach a goal. There can be minor goals such as 'To give a party for friends', or more extensive such as 'To build a new home for my family'. From the analysis of the diaries and interviews, this study resulted in the identification of four general projects: 'To do what is good for my body and soul'; 'To keep my family and social network together'; 'To create something that is nice and for joy'; and finally, 'To keep my mind active'.

\subsection{Methodological considerations}

Malterud, Siersma and Guassora (2015) introduced the concept 'information power' as a guide to adequate sample size for qualitative studies. Information power depends on the aim of the study, sample specificity, use of established theory, quality of dialogue, and the analysis strategy. The aim of this study was quite broad, and the sampling of participants was consecutive. That is, the participants may have rather different experiences besides being treated for breast cancer. Both these conditions indicate the need for a larger number of participants. On the other hand, the study is supported by theory (time geography); the interview dialogue is strong with experienced researchers; and the data collection includes both diary notes from seven consecutive diary days and in-depth qualitative interviews. As such, we felt that fifteen participants were enough to meet saturation for the aim of this study.

\section{Results}

Although some of the women had to handle an everyday life that was heavily influenced by the previous cancer treatment, and others reported no problems due to treatment, they all emphasised everyday life activities and the meaning of them. The following text will elaborate on how these activities constitute the projects. The participants are described in Table 2.

\subsection{To do what is good for my body and soul}

This project consists of different kinds of physical activities. The activities were experienced as positive and necessary for the cancer survivors in one way or another, whether they liked them or not.

The women's narratives dealt with physical activities even though the participants did not use the term 'physical activity' themselves. They went for walks in the neighbourhood, the forest, and the mountains, walked the dog, and went out for bicycling, swimming, yoga, and a fitness centre. Physical activities were expressed as something they had always done and a way that they had always lived their lives. For Maya, fitness for seniors, aerobic, and bicycling prevented pain and stiffness and made her feel better:

"I have done physical activities all my life and was a handball player until I was 50. I have always been a bit tuff, been a ski jumper and participated in most physical activities as young. I like challenges and it is good to be pushed, because sometimes it can be a problem to go out. It is much harder to go out exercising alone than being dragged out by someone else". (Maya)

Mindfulness helped her sleep, and both yoga and mindfulness prevented pain and oedema after the lymph had been removed. To motivate herself to be more physically active, she decided to participate in a big city run.

Other participants went swimming because they felt good with it, and socialising afterwards was as important as the exercise itself. Meeting people over coffee or fruit, they could

\begin{tabular}{|c|c|c|c|c|}
\hline Physical activities & Creative activities & $\begin{array}{l}\text { Activities } \\
\text { for the brain }\end{array}$ & $\begin{array}{l}\text { Activities } \\
\text { in the home }\end{array}$ & $\begin{array}{l}\text { Activities } \\
\text { together with others }\end{array}$ \\
\hline Going for walks & Doing knitting & Doing crosswords & Doing housework & Meeting friends at the café \\
\hline Dancing & Singing in a choir & Doing Sudoku & Making food & $\begin{array}{l}\text { Walking to the kiosk } \\
\text { talking to people }\end{array}$ \\
\hline Picking berries & Gardening & Reading books & $\begin{array}{l}\text { Making cakes for } \\
\text { Christmas }\end{array}$ & Meeting the sewing club \\
\hline Cycling & Doing embroideries & Reading newspaper & Painting the walls inside & $\begin{array}{l}\text { Meeting others at the centre } \\
\text { of the cancer association }\end{array}$ \\
\hline Running & Playing in a corps & Looking at the TV & Doing groceries & Going to church \\
\hline Spinning & $\begin{array}{l}\text { Making it cozy by lightening } \\
\text { a candle, drinking a glass of wine }\end{array}$ & Keeping up with news & $\begin{array}{l}\text { Rehabilitate the cottage } \\
\text { or house }\end{array}$ & $\begin{array}{l}\text { Going to work and meeting } \\
\text { others }\end{array}$ \\
\hline Swimming & Taking photos & & Cleaning the gutter & \\
\hline Pilates & Picking flowers & & & \\
\hline Yoga & Making drawings & & & \\
\hline Walking the dog & & & & \\
\hline
\end{tabular}

Tab. 1: Groups of desirable activities from the diaries and interviews Source: authors' field research 


\begin{tabular}{lclcl}
\hline Participants & Age & Living with someone or alone & Children & Work/Retirement \\
\hline 1 Elisabeth & 48 & With husband & 3 & Disability pension \\
2 Pamela & 56 & With husband & 2 & Working $50 \%$ \\
3 Bridget & 56 & Alone & 1 & Working $100 \%$ \\
4 Evelyn & 59 & Alone & 2 & Working 100\% \\
5 Elsie & 59 & With husband & 1 & Working 100\% \\
6 Cora & 63 & Alone & 0 & Disability pension \\
7 Maya & 66 & With husband & 2 & Disability pension \\
8 Susan & 67 & With husband & 2 & Retired \\
9 Cilia & 68 & Alone & 2 & Retired \\
10 Anna & 70 & With husband & 1 & Retired \\
11 Patty & 72 & With husband & 3 & Retired \\
12 Karen & 73 & With husband & 2 & Retired \\
13 Sophie & 74 & Alone & 2 & Retired \\
14 Brenda & 76 & With husband & 1 & Retired \\
15 Daniela & 86 & Alone & 2 & Retired \\
\hline
\end{tabular}

Tab. 2: The study participants

Source: authors' field reports

share experiences of cancer treatment. In this way, training involved the possibility of sharing experiences and holding on to friendships.

Elisabeth knew that if she was to survive, she had to be fit. She realised that she needed someone to help her in getting out, and she got a dog:

"And that was very smart, because when you get out, and you have warm clothes and coffee you can be out for many hours. We do not go fast, but for many hours. Walking generates so much positivity". (Elisabeth)

Elisabeth did former physical activities in different, adjusted ways, such as co-training with a group of other women:

“... and I can manage to be behind. I just must accept that they run away from me. Doing interval training is ok because then we meet during pauses. Just coming out in fresh air. It makes me see everything in a lighter way". (Elisabeth)

Others started doing physical activities because professionals argued that it was good for their health and could prevent cancer recurrence. They did spin, walking, bicycling, and running together with colleagues and friends. The social aspect of training and the importance of being fit to be able to engage in other activities were important arguments for continuing.

Not all participants were motivated for physical activities. Due to side-effects of treatment, some found it too difficult to start doing any physical activities, even when they knew they should. For some, the door was hard to force open

This general everyday life project deals with different kinds of physical activities that were good for body and soul for those performing activities in these projects. The meaning of the activities was connected to how the cancer survivors had spent their lives previously, as well as to well-being and socialising, and the activities helped them to manage their lives, which promoted energy for other desirable activities.

\subsection{To create something that is nice and for joy}

The aim of this project is to create something that is nice, that involves joy and benefit.
For the oldest women, engaging in handicraft was necessary to get a feeling of doing something useful for the home, for family members, and for others. Also, it was a way of spending time. Daniela and Sophie knitted lap rugs for their grandchildren, and Daniela explained that she had problems being inactive. Susan knitted to fill her everyday life with something positive, and Anna talked about how she had always enjoyed doing handicrafts. She concentrated on voluntary work, selling handicrafts to get money for social events at the nearby nursing home. When asked about the meaning of these activities, she said:

"The day I can't use my hands, it will be difficult. Of course, I could read, doing crosswords and other different things, but handicrafts give me something. I feel that if I just sit there doing nothing (in the house), at least I do this. I do something that is useful to say it like that." (Anna)

Doing handicraft had mixed meanings. The participants managed the activities; the results were nice and positive for other people; they filled the time, and for some it was combined with socialising.

Other creative activities involved similar meanings, such as photo, choir, playing an instrument, making drawings, and picking nice stones and flowers. Cilia started to sing in a choir: "I do it once a week. It is so nice, and I have met a lot of nice people there". Bridget stopped playing an instrument when she married because her husband did not like it. After she got breast cancer and was divorced, she started to play in a corps again, and she loved it.

For Elisabeth, the fact that she had to stop working meant that she experienced new activities. She met new people and had to involve herself in shaping a new everyday life, finding a new passion, and finding time to rest. She attended a photo workshop and said:

"I have found something that gives me meaning and that involves social meeting places. It means that I meet 20 to 25 other people that are as interested in this as I am. We are making a new network and I get new friends. Now I find myself as a very lucky person having the possibilities to do what I like". (Elisabeth) 
During the last years Elisabeth had spent time renovating the house, doing sewing, drawings, and other projects at home or in the cottage. Although she was active and enjoyed a lot of activities, she talked about the need to rest and to adjust the activities due to her capacity. Maya had to learn how to rest in a different way than before and started to do new things such as crosswords and looking at television in the morning.

Although most of these women talked about activities they enjoyed doing and that involved a special meaning for them, such as being creative or socialising, a few talked about the things they would like to do but were unable to initiate. Elsie said that she was full of energy and added:

"I should have had a hobby. I have thought about the Red Cross, may be doing some voluntary work. I will make them a call and ask what that will involve; I have a lot of energy." (Elsie)

This general everyday life project included creative activities, which the women prioritised, activities they were used to doing or liked to do, and activities they had just learned about or picked up from former life. The activities often involved gifts to others, socialising, and ways of getting rest.

\subsection{To keep the family and social network together}

This project was of great importance, as well as demanding. The participants expressed the importance of being cared for when they needed it, spending time with family and friends, and being open about diagnosis, treatment, and the situation afterwards. Although Evelyn loved the way friends and family had supported her, she sometimes felt that there were too many visitors and social situations she had to attend. Sometimes it was difficult to have time for herself. Spending time with and caring for children can be strenuous, but it was a priority for those with grandchildren. That was also the case when gathering the family for dinner. Susan wrote comments in her diary when she had spent time with others: 'so good to be together', 'lovely', 'indescribably', 'lovely people', and 'cosy'. She said:

"I have always been a social person, but I use a lot of energy to be nice, to make it a bit cosy. And they (the family) knows me, and they can see, and they say that I should take a rest, go and lay down for a while. But I don't want to do that, I would so much be like the rest of them, like it was before". (Susan)

Even though Susan had support from her family in encouraging her to take care of herself, it was difficult for her to rest. Despite less energy she kept up with what she had always done; she invited friends and family, and she felt exhausted before they arrived. She said:

"I expect a lot from myself and it easily gets too much with a lot of people talking and children running around asking for equipment for drawing ... I do it because I am a family person wanting to have the family around me. I have always been the one that have gathered them and done everything when there was something to celebrate. I feel that it is more strenuous now, I put off and get bad conscience about it". (Susan)

Inviting family and friends involves different kinds of activities regarding preparing and cleaning up. Meeting family members at other places such as a café did not demand that much energy. Although friends were important, Pamela said:
"I think I am a bit different now than before. I can feel that I don't take that much contact with the ones that don't give me anything. In a way I am a bit careful. My life is too short to have people around me that only suck out my energy". (Pamela)

The women negotiated with themselves as to whether they should go on doing activities that exhausted them. Pamela refused to do them and decided not to spend time with people who made her tired, and Susan said 'yes' more often than she thought was wise. Reducing the number of initiatives could make the women feel better, but it also represented a risk, as fewer social gatherings could have consequences for their social networks.

In this general everyday life project the women were concerned about the importance of gathering family members. For some, these social situations had always been their responsibility, and they wanted this to continue. Less energy and extended need for rest made this more challenging. Some of the participants continued meeting important family and friends outside home, which for them were less demanding.

\subsection{To keep my mind active}

This project involved activities that emphasised concentration or learning, and for some this meant challenging capacity restrictions. Sudoku, crossword, as well as reading newspapers and books, were activities they had liked to do earlier. The activities were 'good for the brain' or 'keep the brain in good shape', which were new reasons for keeping up with them. To manage many of the activities, concentration and silence in the room was necessary, and they experienced the activities as more time consuming than before.

For some, reading newspapers was a way of using the brain, and more importantly, it was necessary to be able to participate in conversations with other people. Not being up to date meant that these social situations were difficult for them. Concentrating and remembering what they had heard or read was a challenge for some, and Pamela expressed:

"I remember very little, names and so on. Maybe it is my age, but ... and the concentration is not the same. If this happened after the treatment I don't know, but I think it was so". (Pamela)

Concentrating to manage some activities demands energy and a willingness to persevere despite challenges. Most of the participants continued with these activities because they appreciated them, but also because keeping the brain active was important to be able to do other desirable activities, such as discussing the news with friends or enjoying a book.

This general project dealt with activities that stimulated concentration and remembering. Although these activities were a continuation of what they had prioritised before illness too, central now were the importance of being able to participate in conversations with other people.

\section{Discussion}

Experiencing a life-threatening illness involves changes and readjustments in life. The women facing late effects after treatment talked about changes in life priorities, lifestyle readjustments, and specific strategies, as found in other studies (Lindberg et al., 2015; Salander et al., 2011; Volker, 2013). The women in the present study spent time on a myriad of prioritised activities, and from a timegeographic perspective we identified four different projects: 
1) To do what is good for my body and soul; 2) To create something that is nice and for joy; 3) To keep my family together; and 4) To keep my mind active. Among the activities in these projects, there were desirable activities (which were identified from the diaries, see Tab. 1), and other activities that were not perceived as desirable. Each of the four projects contains activities with a special meaning to the individual and has therefore to be obtainable. Performing activities can be an expression of identity and therefore act as a support in the process of redefining and recognising oneself. The women in the present study needed to adjust their expectations in order to find a balance that enabled them to continue with meaningful activities. Based on these findings, two distinctive features of the daily life of the participating women will be discussed: Redefining identity in activities; and Activity balance.

\subsection{Redefining identity in activities}

As activities are linked to identity (Christiansen and Townsend, 2014), a person's individual identity may be challenged by illness, making it difficult to keep up former activities at work, home, or during leisure time. The four projects indicated how important activities had strong connections to the breast cancer survivors' individual histories. Additionally, the projects displayed how the women wanted to present themselves in a positive way and how this ability was an important element in the feeling of wellness and having a good quality of life.

The projects also identified stories of activities that link together earlier life with today's everyday life for cancer survivors. Susan continued to invite the family for dinner, while others continued reading or caring for grandchildren, even though it was strenuous. Despite bodily restrictions, the continuation of activities enabled the women to present themselves in a desirable way and can be understood as a process of redefining and shaping their individual identities. These processes have been described as ways of experiencing continuity in life (Palmadottir, 2010) and working toward normalcy (Walker et al., 2015). In the latter study, a greater sense of normalcy was associated with higher engagement in valued activities and increased physical and psychological well-being. The women in the current study appreciated activities that presented them as the same person they were before the cancer, a desire expressed by statements like 'to be like others' and 'to be like before'. The four projects are expressions of how activities helped the women to experience lives as near to their former lives as possible. The importance of being perceived by others as having an identity beyond that of a cancer survivor is also described in other studies (Lavallée et al., 2019; Ridner et al., 2012; Walker et al., 2015).

The importance of socialising during activities was clearly expressed through the four projects, for example, singing in a choir, doing activities with grandchildren, chatting after physical training, and doing handicrafts as volunteer work. Since activities are connected to identity, performing desirable activities while socialising may therefore be helpful in the process of redefining oneself after cancer. The importance of socialising through activities is in line with other studies. Some of the women in a study by Palmadottir (2010) found it rewarding to be active in cancer organisations, contributing to the well-being of other people in similar situations, while Lavallée et al. (2019) found that how meeting others in similar situations encouraged the women to continue with organisational work, share experiences, and receive support.
Supportive environments are also shown to be important in the healing process after cancer (English et al., 2008; Palmadottir, 2010; Volker et al., 2013).

\subsection{Activity balance}

The four projects represented prioritised, but also negotiated, activities. To find a balance in daily activities, one should be able to organise and participate in accordance with one's wishes and values (Backman, 2014). Due to the late effects of treatment, however, some activities were hard to follow, and the participants had to argue with themselves about how to manage these desired but demanding activities. The breast cancer survivors in the present study found it challenging to balance activities that had a special meaning, such as spending time with family members, which often resulted in an overuse of energy and exhaustion. Similarly, the young adult cancer survivors in the study of Hauken et al. (2013), struggled to find a balance between everyday activities, and they experienced that some activities were important in order to build capacity, while others were prioritised to increase social participation. Such priorities could be essential for establishing activity balance in accordance with one's wishes and values, as emphasised in Backman (2014). Activity balance involves leaving some activities out and replacing them with others. Finding balance in activities is an individual process, and each person must decide what that means for her or him, as shown in our study when Elisabeth had to stop working as a banker and started working with photography. Changes in activity balance are described as learning to live under new conditions and reevaluating one's capacity in different activities (Hauken et al., 2013), which may involve a reorientation of everyday life, as found in Jakobsen et al. (2017) and Salander et al. (2011). Working towards a balance in daily activities involves the risk of eliminating desirable projects with activities that confirm identity or socialising activities with significant persons. Doing more activities than advisable could for some prevent these losses but would not be a sustainable strategy. Involving activities that are both enjoyable and provide opportunities for rest, for instance, the project 'To create something that is nice and for joy', could be a way of balancing the capacity of everyday activities as well as confirming former identity.

\subsection{Strengths and limitations}

The present study illustrates how time-geographic diaries supplemented by interviews, can be suitable to highlight desirable everyday life projects with associated activities that positively influence individuals' quality of life. First, the diaries help people to remember their everyday activities in detail and was thus a perfect tool to facilitate the interviews. Second, the diaries themselves may also clarify critical elements that have to be handled in order to live good lives. The time-geographic diary method emphasises the individual's own description of everyday life and is of raising consciousness of the person's own life, and the constraints the person faces. Prioritised activities often represent part of the women's histories and are therefore essential in the process of redefining identity after cancer treatment. Social relationships in activities seem to be fundamental, along with the individuals' negotiating in order to achieve the optimal activity balance.

Our sample was breast cancer survivors that struggled with different health issues. Results from our qualitative study cannot be generalisable to the entire population of breast cancer survivors. The results can be generalised to 
similar settings, however, in which adult women struggle with various chronic conditions, and thus be applicable beyond the breast cancer survivor setting.

The present study has some limitations. Most of our participants were retired and only one third had active work lives. Thus, our identified projects and activities are most likely valid for an older breast cancer survivor population. Despite that, many elements in these projects are universal and probably generalisable to the youngest survivors: we encourage future work to explore similar research questions in a younger or working-age breast cancer population.

\section{Conclusion}

To summarise, with the help of time-geographic diary notes and in-depth semi-structured interviews, this study identified four projects of everyday life activities for breast cancer survivors: 1) To do what is good for my body and soul; 2) To create something that is nice and for joy; 3) To keep my family and social network together; and 4) To keep my mind active. The projects hold activities that represented important aspects of the women's lives and identities. Due to treatment effects, some of the participants had to stop doing activities as before. To be able to do what was most important, they had to balance the activities in a manageable way. Findings show how these four projects with meaningful and prioritised activities define and redefine identity and challenge activity balance in ways that improve quality of life.

The implications of our findings may be directed to the growing need for more individualised follow-up programs after breast cancer and the need for rethinking how followup could be sustained. The concept of patient empowerment in cancer follow-up can be conceptualised as mastery, skills and knowledge (Johnsen et al., 2017). When developing interventions or actions, based on patient involvement, however, one should ensure that the interventions are not only efficient, but also feasible to all patients - not only the well-educated with a strong social network (Johansen and Dalton, 2017). Rehabilitation stays are valuable for many breast cancer survivors (Juvet et al., 2009), but unfortunately, they are not accessible or even desirable for others. Knowledge of how everyday life projects with a balance of desired activities can stimulate positive identity and good quality of life may provide building blocks for developing more individual and low-threshold healthcare services. Such services could even be facilitated by peers (Freund, 2016, Johansen and Dalton, 2017), and thus be available for all breast cancer survivors, either alone or in combination with existing rehabilitation programs.

\section{Acknowledgements}

We wish to acknowledge the Norwegian University of Science and Technology (NTNU) for funds that enabled us to carry out this project. We also wish to thank Dr. Med. Steinar Lundgren for recruiting the patients, and the patients for sharing their stories of life after breast cancer.

\section{References:}

ANGUERA, M. T., BLANCO-VILLASENOR, A., LOSADA, J. L., SÁNCHEZ-ALGARRA, P., ONWUEGBUZIE, A. J. (2018): Revisiting the difference between mixed methods and multimethods: Is it all in the name? Quality \& quantity, 52(6): 2757-2770.
BACKMAN, C. L. (2014). Occupational Balance and Wellbeing. In: Christiansen, C., Townsend, E. A. [eds.]: Introduction to occupation: The Art of science and living (pp. 209-227). Harlow, Pearson Education.

CHENG, K. K. F., LIM, Y. T. E., KOH, Z. M., TAM, W. W. S. (2017): Home-based multidimensional survivorship programmes for breast cancer survivors. Cochrane Database of Systematic Reviews, (8).

CHRISTIANSEN, C. H. (1999): Defining lives: occupation as identity: An essay on competence, coherence, and the creation of meaning. American Journal of Occupational Therapy, 53(6): 547-558.

CHRISTIANSEN， C. H., TOWNSEND， E. A. (2014): An introduction to occupation. In: Christiansen, C., Townsend, E. A. [eds.]: Introduction to occupation: The Art of science and living (pp. 1-34). Harlow, Pearson Education.

DENMARK-WAHNEFRIED， W., PINTO， B. M., GRITZ, E. R. (2006): Promoting Health and Physical Function Among Cancer Survivors: Potential for Prevention and Questions That Remain. Journal of Clinical Oncology, 24(32): 5125-5131.

ELLEGÅRD, K. (2019): Introduction. The roots and diffusion of time-geography. In: Ellegård, K. [ed.]: Time Geography in the global context. An Anthology (pp. 1-18). London, Routledge.

ELLEGÅRD, K., NORDELL, K. (1997): Att byta vanmakt mot egenmakt, p. 143. Stockholm, Johansson \& Skyttmo Förlag.

ELLEGÅRD, K., WIHLBORG, E. (2001): Metoder för att studera och analysera vardagen. In: Ellegård, K. et al. [eds.]: Fånga vardagen. Ett tvärvetenskapligt perspektiv (pp. 5-12). Lund, Studentlitteratur.

ELLEGÅRD, K. (1999): A time-geographical approach to the study of everyday life of individuals - A challenge of complexity. GeoJournal, 48 (3): 3167-175.

ENGLISH, J, WILSON, K., KELLER-OLAMAN, S. (2008). Health, healing and recovery: Therapeutic landscapes and the everyday lives of breast cancer survivors. Social Science and Medicine, 67(1): 68-78.

FREUND, K. M. (2016): Implementation of evidencebased patient navigation programs. Acta Oncologica, 56(2): 123-127.

GUBRIUM, J. F., HOLSTEIN, J.A. (1997): The New Language of Qualitative Method. Oxford, Oxford University Press.

HAUKEN, M. A., HOLSEN, I., FISMEN, E., LARSEN, T. M. B. (2013): Participating in Life again. Cancer Nursing, 37(4): E48-E59.

HASSELKUS, B. R. (2006): The world of everyday occupation: Real People, Real Lives. American Journal of Occupational Therapy, 60(6): 627-640.

HSIEH, H. F., SHANNON, S. E. (2005): Three Approaches to Qualitative Content Analysis. Qualitative Health Research, 15(9): 1277-1288.

HÅKANSSON, C., MORVILLE, A. L., WAGMAN, P. (2017): Aktivitetsbalance. In: Kristensen, H. K., Schou, A. S. B., Mærsk, J. L. [eds.]: Nordisk aktivitetsvidenskab (pp. 111-127). København, Munksgaard.

JAKOBSEN, K., MAGNUS, E., LUNDGREN, S., 
REIDUNSDOTTIR, R. J. (2017): Everyday life in breast cancer survivors experiencing challenges: A qualitative study. Scandinavian Journal of Occupational Therapy, 25(4): 298-307.

JARMAN, J. (2014): What is occupation? Inter disciplinary perspectives on defining and classifying human activity. In: Christiansen, C., Townsend, E. [eds.]: Introduction to occupation: The art of science and living (pp. 59-77). Essex, UK, Pearson.

JOHANSEN, C., DALTON, S. O. (2017): Survivorship in new harbors. Acta Oncologica, 56(2): 119-122.

JOHNSEN, A. T., ESKILDSEN, N. B., THOMSEN, T. G., GRǨNVOLD, M., ROSS, L., JØRGENSEN, C. R. (2017): Conceptualising patient empowerment in cancer followup by combining theory and qualitative data. Acta Oncologica, 56(2): 232-238.

JUVET, L. K., ELVSAAS, I. K. Ø., LEIVSETH, G., ANKER, G., BERTHEUSSEN, G. F., FALKMER, U., FORS, E. A., LUNDGREN, S., OLDERVOLL, L. M., THUNE, I., NORDERHAUG, I. N. (2009): Rehabilitation of breast cancer patients [online]. Norwegian Knowledge Centre for Health Services Available at: https://fhi.brage. unit.no/fhi-xmlui/bitstream/handle/11250/2378226/ NOKCrapport2_2009. pdf? sequence $=2$

KAMPSHOFF, C. S., JANSEN, F., VAN MECHELEN, W. MAY, A. M., BRUG, J., CHINAPAW, M. J. M., BUFFART, L. M. (2014): Determinants of exercise adherence and maintenance among cancer survivors: a systematic review. International Journal of Behavioral Nutrition and Physical Activity, 11(1): 80.

LALIBERTE RUDMAN, D. (2002): Linking occupation and identity: Lessons learned through qualitative exploration. Journal of Occupational Science, 9(1): 12-19.

LAVALLÉE, J. F., ABDIN, S., FAULKNER, J., HUSTED, M. (2019): Barriers and facilitators to participating in physical activity for adults with breast cancer receiving adjuvant treatment: A qualitative metasynthesis. Psycho-Oncology, 28(3): 468-476.

LINDBERG, P., KOLLER, M., STEINGER, B., LORENZ, W., WYATT, J. C., INWALD, E. C., KLINKHAMMERSCHALKE, M. (2015). Breast cancer survivors' recollection of their illness and therapy seven years after enrolment into a randomized controlled clinical trial. BMC Cancer, 15(1): 554 .

MAGNUS, E. (2019). The time-geographic diary method in studies of everyday life. In: Ellegård, K.: Time geography in the global context. An anthology (pp. 134-154). London, Routledge.

MALTERUD, K., SIERSMA, V. D., GUASSORA, A. D. (2015):
Sample Size in Qualitative Interview Studies: Guided by Information Power. Qualitative Health Research, 26(13): 1753-1760.

McDOUGALL, G. J, OLIVER, J. A. S., SCOGIN, F. (2014): Memory and Cancer: A Review of the Literature. Archives of Psychiatric Nursing, 28(3): 180-186.

PALMADOTTIR, G. (2010): The role of occupational participation and environment among Icelandic women with breast cancer: A qualitative study. Scandinavian Journal of Occupational Therapy, 17(4): 299-307.

PUYMBROECK， M. V., BURK， B. N., SHINEW， K. J., KUHLENSCHMIDT, M. C., SCHMID, A. A. (2013): Perceived Health Benefits from Yoga Among Breast Cancer Survivors. American Journal of Health Promotion 27(5): 308-315.

RIDNER, S. H., BONNER, C. M., DENG, J., SINCLAIR, V. G. (2012): Voices from the Shadows. Living with Lymphedema. Cancer Nursing 35(1): 18-26.

SADEGHI, E., GONZALI, N., TABRIZI, F. M. (2016): Effects of Energy Conservation Strategies on Cancer Related Fatigue and Health Promotion Lifestyle in Breast Cancer Survivors: A Randomized Control Trial. Asian Pacific Journal of Cancer Prevention, 17(10): 4783-4790.

SALANDER, P., LILLIEHORN, S., HAMBERG, K. KERO, A. (2011): The impact of breast cancer on living an everyday life 4.5-5 years post diagnosis - a qualitative prospective study of 39 women. Acta Oncologica, 50(3): 399-407.

STOUTEENBERG, M., CUTRONO, S., PERRY, A. (2011): From surviving to thriving: A health and wellness colloquium for breast cancer survivors. Journal of Cancer Education, 26(4): 694-700.

TOWNSEND, E. (1997): Occupation: Potential for personal and social transformation. Journal of Occupational Science, 4(1): 18-26.

VOLKER, D. L., BECKER, H., KANG, S. J., KULLBERG, V. (2013): A Double Whammy: Health Promotion Among Cancer Survivors With Preexisting Functional Limitations. Oncology Nursing Forum, 40(1): 64-71.

WAGMAN, P., HÅKANSSON, C., BJÖRKLUND, A. (2012): Occupational balance as used in occupational therapy: A concept analysis. Scandinavian Journal of Occupational Therapy, 19(4): 322-327.

WALKER, R., SZANTON, S. L., WENZEL, J. (2015): Working Toward Normalcy Post-Treatment: A Qualitative Study of Older Adult Breast and Prostate Cancer Survivors. Oncology Nursing Forum 42(6): E358-367. 